\title{
Numerical analysis of mixed mode I/II stress intensity factors of edge slant cracked plates
}

\author{
A. S. Fayed ${ }^{*}$
}

Mechanical Engineering Department, Jazan University, KSA on sabbatical leave from Materials Engineering Department, Faculty of Engineering, Zagazig University, Egypt

\begin{tabular}{l}
\hline A R T I C L EI N F O \\
\hline Article history: \\
Received 6 March, 2016 \\
Accepted 5 August 2016 \\
Available online \\
5 August 2016 \\
\hline Keywords: \\
Stress intensity factor \\
Mixed mode I/II \\
Slant edge crack \\
Crack initiation angle \\
Two dimensional finite element \\
\end{tabular}

\section{A B S T R A C T}

\begin{abstract}
Mixed mode I/II stress intensity factors of an edge slant-cracked plate under tensile loading were assessed. A two-dimensional finite element analysis was employed using ABAQUS. Various crack lengths and angles were analyzed. The effect of the crack location at the plate edge was also examined. Crack initiation angles were calculated. In general, modes I and II stress intensity factor increase with increasing crack length. However, the rate of increase in mode I SIF decreases with increasing the main crack angle. The results showed that stress intensity factors decreased ad the crack mouth approaches the edge mid line. The crack location becomes more significant as the crack length increases. The angle of first cracking depends on crack length, location, and angle.
\end{abstract}

(C) 2017 Growing Science Ltd. All rights reserved.

\section{Introduction}

Due to the vast development in engineering structures, cracks may exist under complex state of loading. A failure may occur despite of the validity of strength of materials and elasticity theory. Therefore, a wide development in crack propagation study is needed in the fracture mechanics filed. Mixed mode crack propagation is a vital in fracture mechanics. This includes the determination of crack initiation angles which describe the first instant of cracking path. Several criteria were proposed in many researchers to address and to predict the crack initiation angle in loading leading to I/II mixed mode fracture at the crack tip (Khan \& Khraisheh, 2000; Ayatollahi \& Aliha, 2009; Mirsayar et al., 2014; Mirlohi \& Aliha, 2013; Mirsayar \& Samaei, 2014; Aliha et al., 2010, 2013; Aliha, \& Ayatollahi, 2012). Many criteria are used to understand the fracture behavior of materials under mixed mode I/II loading conditions such as maximum tangential stress (Erdogan \& Shi, 1963), minimum strain energy density (Sih \& Macdonald, 1974), maximum energy release rate (Hussain, 1974; Nuismer, 1975) and 
maximum tangential strain (Chang, 1981). Numerous experimental and numerical analyses were performed and various types of specimens (Arcan et al., 1978; Richard \& Benitz, 1983; Ayatollahi \& Aliha, 2009, 2011; Aliha \& Ayatollahi, 2013; Mirsayar, 2014; Akbardoost, 2014; Akbardoost et al., 2014; Abd-Elhady, 2013; Aliha et al., 2015a, b, 2016a,b) were introduced by researchers and used in experimental analyses. Stress intensity factor, SIF, for crack surfaces under opening mode in a linearelastic solid can be determined by extrapolations-based methods or energy-based methods. Energybased methods such as J-Integral, energy release are extensively utilized in many references (Kanninen \& Popelar, 1985; Tada et al., 2000) and commercial finite element, FE codes (ANSYS, FRANC2D, ABAQUS).

Determination of SIF and strain energy release rate by FE method requires either employing special elements to capture the stress singularity near the crack tip or generating a refined mesh around the crack tip. Analysis with conventional elements near the crack tip needs very small elements to capture the stress behavior at crack tip (Hammouda et al., 2002, 2004, 2007; Fayed, 2008). To avoid such refined mesh, Hanshell and Shaw (1975) and Barsoum $(1976,1977)$ proposed a special element to correctly address the crack tip singularity. Bhadauria et al. (2010) used ANSYS to numerically calculate the SIF for mixed mode (I/II) fracture for an inclined edge crack with crack angles of $0^{\circ}, 15^{\circ}, 30^{\circ}, 45^{\circ}$, and $50^{\circ}$. They utilized six different crack initiation angle criteria with the estimated SIF to predict the crack initiation angle. They concluded that the material behaved in a brittle manner as the crack inclination angle increased. Petit et al. (1996) evaluated the mixed mode I/II SIFs, $\mathrm{K}_{\mathrm{I}}$ and $\mathrm{K}_{\mathrm{II}}$, and simulated the crack propagation for an inclined edge crack panel with crack angle of $45^{\circ}$. They obtained the displacement field through FE method. Ayhan (2004) utilized three-dimensional enriched FE to estimate mixed mode SIFs for deflected and inclined surface cracks in finite-thickness plates under uniform tensile remote loading. However, the problem of slant cracks with offset positions from plate center has not been widely numerically addressed by finite element techniques. Thus, the main objective of the present work is to quantify the known effect of crack position on mixed mode I and II SIFs of opened cracks in tension. Therefore, a mixed mode finite element analysis was carried out using the ABAQUS finite program on an edge-slant crack under uniaxial loading. Mode I/II stress intensity factors in various crack position along the plate height were examined. The effect of crack length and main crack inclination angle was considered. The crack initiation angles were also determined.

\section{Present finite element idealization}

Inclined edge crack in a plate under tensile loading was analyzed. A full model of the plate was utilized because of the unsymmetrical model. The finite element program ABAQUS 6.14 was utilized. The present model was adopted to examine the mixed mode I/II fracture behavior of the crack. The investigation was performed under load control and plane stress conditions.

As illustrated in Fig. 1a, the plate was $200 \mathrm{~mm}$ height, $2 \mathrm{H}, 100 \mathrm{~mm}$ width, $W$. Crack length, $a$, to plate width ratios, $a / W$, of $0.1,0.2,0.3,0.4$, and 0.5 were analyzed with a crack angle, $\beta$, ranging from zero to $75^{\circ}$ measured in a counterclockwise from the horizontal axis. Different relative crack positions, $h$, to plate height, i.e. $h / H$, ranging from 0 to 0.8 in a step of 0.1 were analyzed. The plate was modeled for an isotropic material with modulus of elasticity, $E=206 \mathrm{GPa}$, and Poisson's ratio, $v=0.3$. To successfully capture the stress gradients (as recommended in ABAQUS User's Manual, 2014), CPS8; a generally adopted 8-node biquadratic plane stress quadrilateral with fully integrated elements type having two degrees of freedom in $x$ and $y$ directions were used. The crack tip approached to the boundary of the specimen when crack position was close to top of the plate. Thus, the radius of relevant elements was purposely devised such that the effect of the boundary was minimized. 


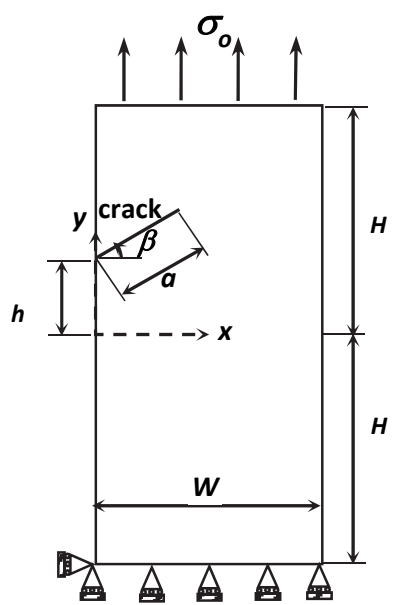

(a)

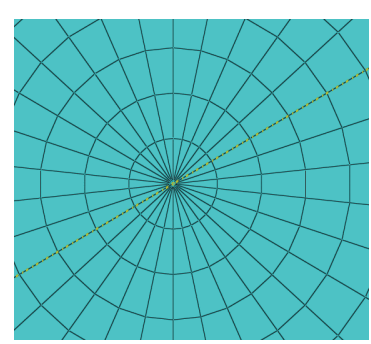

(b)

Fig. 1. A typical example of the present idealization; (a) The general dimensions of the model with the boundary conditions, (b) A part of the mesh at crack tip region

The plate was loaded with a uniform tensile axial stress, $\sigma_{o}=10 \mathrm{MPa}$, applied at its upper surface. The bottom surface was restricted along the $y$-direction and one node, at $x=0$ and $y=-H$, was further restricted in both directions as shown in Fig. 1(a). A typical example of the present idealization associated with the shape of elements at the crack tip region is shown in Fig. 1(b). A singular strain field generates at the crack tip. The calculation accuracy of the stress and strain and the contour integral will be enriched by considering singularity. Such singularity was considered by modeling the crack tip region with a ring of triangles as shown in Fig. 2. Thus, the numerically calculated stress field near the crack tip should evidence the $r^{-1 / 2}$ radial stress distribution.
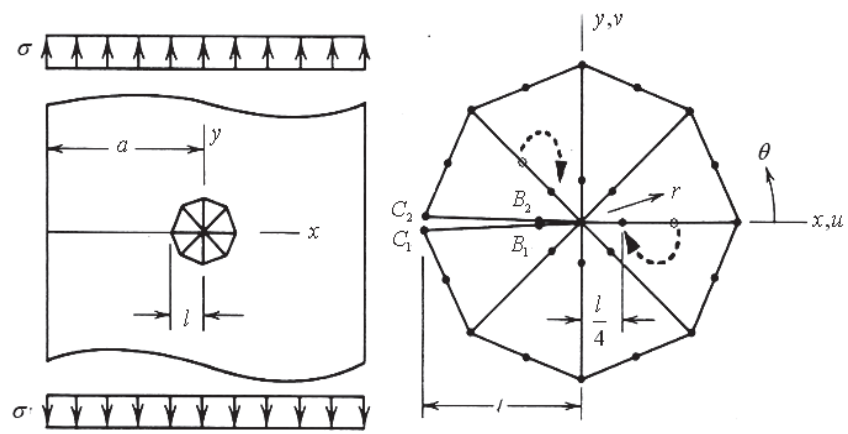

Fig. 2. Quarter node element at crack tip

The following formulae was used to calculate the normalized stress intensity factors, $Y_{I}$ and $Y_{I I}$

$$
\begin{gathered}
Y_{I}=\frac{K_{I}}{\sigma_{o} \sqrt{\pi a}} \\
Y_{I I}=\frac{K_{I I}}{\sigma_{o} \sqrt{\pi a}}
\end{gathered}
$$

where:

$K_{I}$ is mode I stress intensity factor

$K_{I I}$ is mode II stress intensity factor $a$ is crack length

$\sigma_{o}$ is the applied tensile stress 
The prediction of the crack deflection angles was based on the maximum strain energy release rate criterion. The maximum energy release rate criterion postulates that an ideally elastic solid fractures along the plane, oriented at an angle to the plane of the pre-crack, which maximizes the energy release rate. Linear elastic analysis was performed.

\section{Results and Discussion}

In the case of a single straight edge crack panel under pure opening mode I SIF, i.e. $\beta=$ zero, the following closed form solutions is used for calculating the SIF when $a / W \leq 0.6$ (Tada et al., 2000).

$$
K_{I}=Y_{I} \sigma_{o} \sqrt{\pi a}
$$

where $Y_{I}$ is the geometry correction factor and it is usually a function of both crack length, $a$, and panel width, $W . Y_{I}$ is calculated for the case of straight single edge crack is in the middle of the plate's height, i.e. $h / H=0$, as (Tada et al., 2000):

$$
Y_{I}=1.122-0.231\left(\frac{a}{W}\right)+10.55\left(\frac{a}{W}\right)^{2}-21.71\left(\frac{a}{W}\right)^{3}+30.382\left(\frac{a}{W}\right)^{4}
$$

For this case, Fig. 3 shows a close agreement between the present results in the case of single edge crack at $\beta=0^{\circ}$ with the results of both formula (4) (Tada et al., 2000) and Azlan and Ismail (2014) in the case of $h / H=0$ and different crack length, $a / W$. Therefore, the present model was adopted for the following analysis.

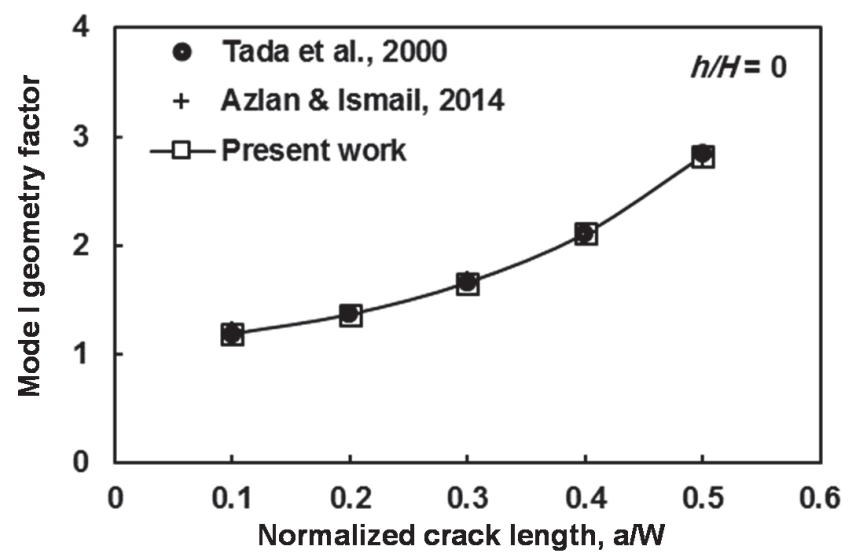

Fig. 3. Geometry correction factor, $Y_{I}$, for single horizontal edge crack at different crack lengths, $a / W$ in the case of $h / H=0$ : A comparison

Fig. 4 illustrates the effect of the size of the crack and the crack angle on mode I and mode II SIFs, respectively, $K_{I}$ and $K_{I I}$, in the case of $h / H=0$. Fig. 4(a) shows that, for the same crack size, as crack angle, $\beta$, increases $K_{I}$ decreases and tends to be zero at $\beta=90^{\circ}$. For the same $\beta$, as crack length increases, $K_{I}$ increases. The rate of increase of $K_{I}$ is more significant at small crack angles. However, for $\beta>60^{\circ}$, as the crack angle increases the crack length has no pronounced effect on $K_{I}$. The decrease in $K_{I}$ with increasing $\beta$ is due to the expected decrease in the contribution of the force acting normal to the crack surface. Fig. 4(b) illustrates that $K_{I I}$ values increase from zero at $\beta=0^{\circ}$ to reach a maximum value followed by a decrease in $K_{I I}$ towards zero at $\beta=90^{\circ}$. For all the analyzed crack lengths, the maximum value was nearly in in the range $30^{\circ}<\beta<50^{\circ}$. Further, as the crack length increases, mode II SIF increases. For higher crack inclination angles, i.e. $\beta>60^{\circ}$, the rate of increase of $K_{I I}$ is relatively low as $a / W$ increases. 
A comparison is shown in Fig. 5 between the present results and relevant data due to Theocaris and Papadopoulos, (1984) who calculated $K_{I}$ for slant cracks with crack angles ranging from $0^{\circ}$, to $75^{\circ}$. A good agreement is noticed. Fig. 6 depicts the mixed mode I/II SIFs for various crack positions, angles and lengths. In general, as crack position changes from 0 to 0.9 , mode I SIF increases. That increase depends on the crack angle and length. In other words, mode I SIF increases slightly at a certain range of $h / H$ beyond which the increase becomes sharp to reach a maximum value at $h / H=y_{s t}$ dependent on both crack angle and length. $y_{s t}$ represents the crack position at which the increase in mode I SIF becomes sharp. For $a / W=0.1$, mode I and II SIFs increase slightly in the range from $h / H=0$ to $h / H=$ 0.6 followed by a rise to maximum values at $h / H=0.8$ for all the analyzed crack angles. However, for $a / W=0.3$ and 0.5 , the position, $y_{s t}$, changes with changing the crack angle and the rise becomes steeper at higher angles. For an example at $a / W=0.3$, for $\beta=0^{\circ}, 15^{\circ}, 30^{\circ}, 45^{\circ}, 60^{\circ}$ and $75^{\circ}, y_{s t}$ takes place, respectively, at $h / H=0.6,0.5,0.4,0.3,0.2$, and 0.1 . As the crack length increases, the effect of crack position becomes more pronounced.
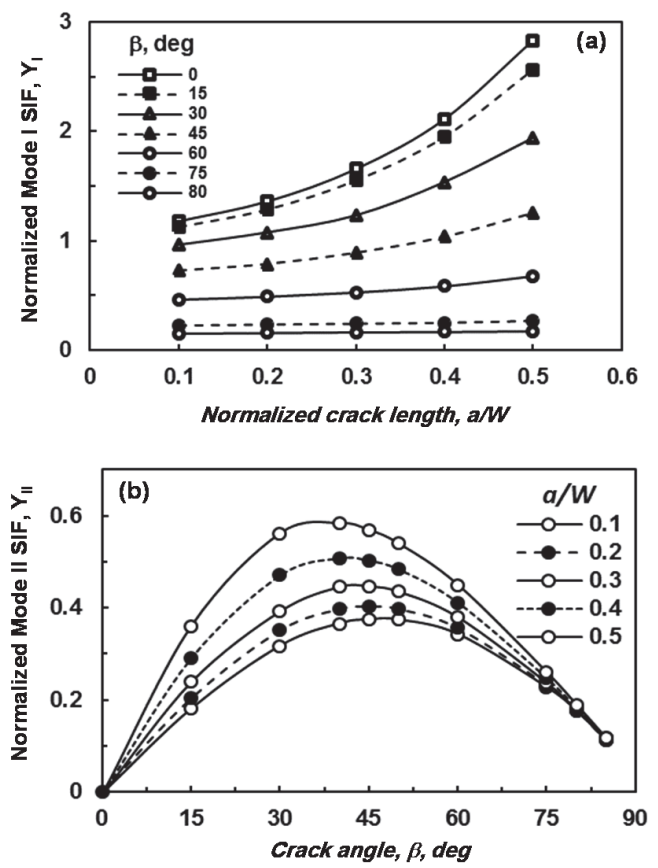

Fig. 4. Normalized mode I and II SIFs, $Y_{I}$ and $Y_{I I}$, respectively, for slant edge crack at different crack lengths, $a / W$, in the case of $h / H=0$

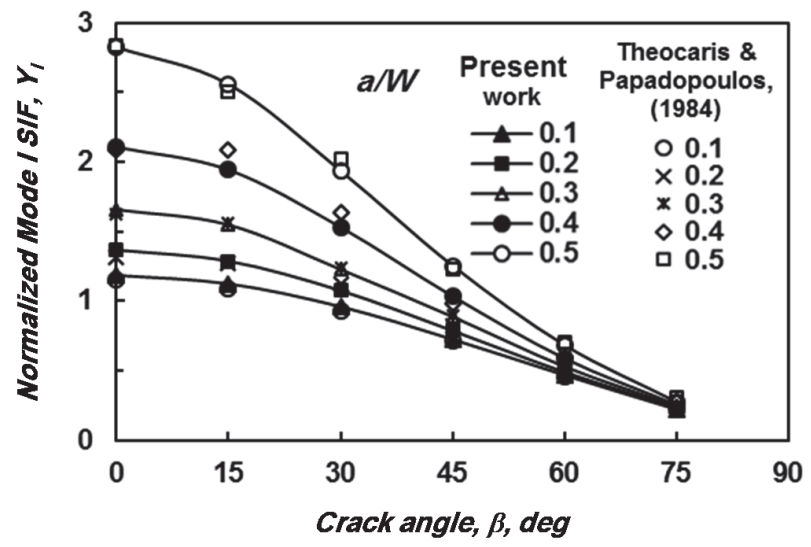

Fig. 5. Normalized mode I SIFs for slant edge cracks at different crack lengths $(a / W)$ in the case of $h / H=0$ 
To clarify the effect of crack position on mode II SIF, Fig. 7a is an example in the case of $a / W=$ 0.3 and $h / H$ changes from 0 to 0.6 . It can be noticed that for $45^{\circ}>\beta>0^{\circ}$ there a slight decrease of mode II SIF as $h / H$ increases at $h / H<0.3$ after which the rate of decrease increases to reach a minimum at $h / H=0.6$. On the other hand, for $\beta>45^{\circ}$, there is an increase of mode II SIF with increasing $h / H$. For the same $h / H$, mode II SIF increases with increasing crack angle to reach a maximum followed by a decrease in mode II SIF. The maximum values were about in the range of $40^{\circ}<\beta<50^{\circ}$ for $h / H \leq 0.4$. While, for $h / H>0.4$, maximum mode II SIF occurs nearly at $\beta=60^{\circ}$, Fig. 7b. The effect of $a / W$ and $\beta$ on the crack initiation angle, $\theta$, is described in Fig. 8 . For the same crack angle at position $h / H=0$, an increase in $a / W$ does not result in a pronounced effect on the predicted value of $\theta$. There is a good agreement between the present crack initiation results at $\mathrm{h} / \mathrm{H}=0$ and the data found due to Ewing et al. (1976).
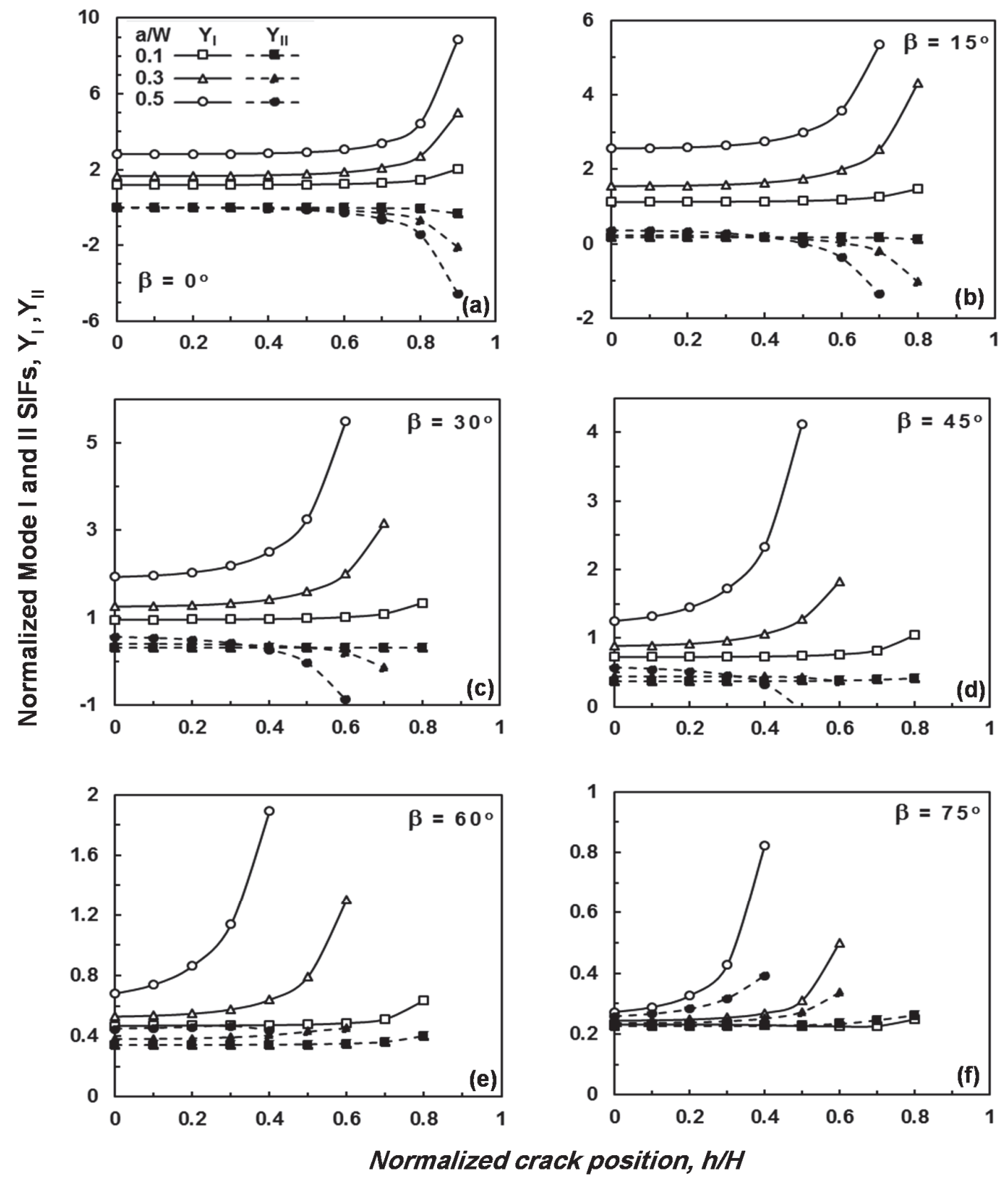

Fig. 6. Normalized mode I and II SIFs for slant edge cracks at different crack positions,$h / H$, and various crack lengths,$a / W$,with different crack angles , $\beta$ 

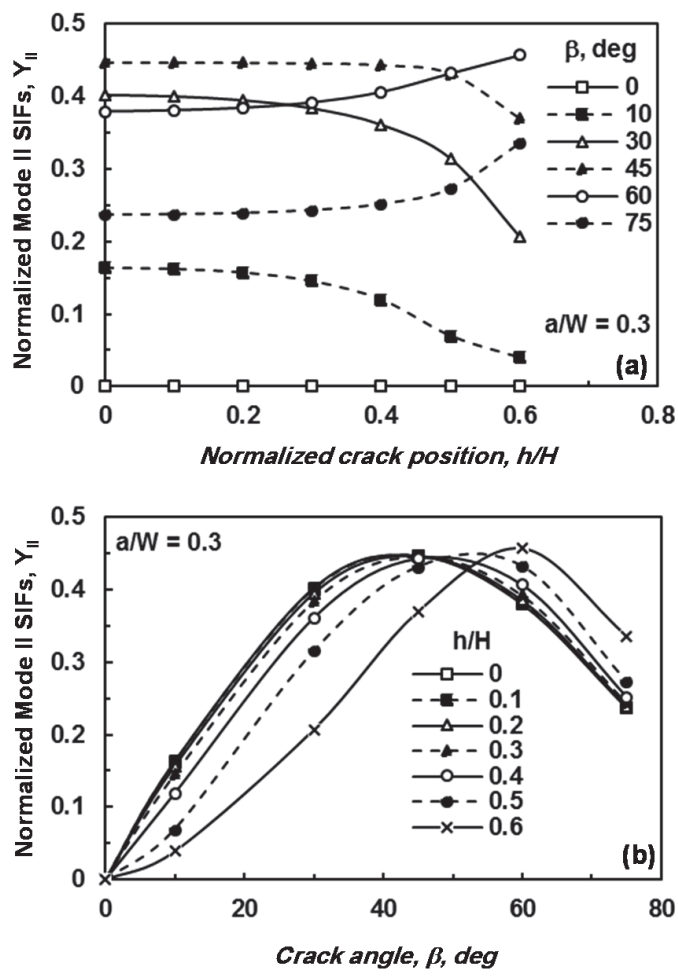

Fig. 7. Effect of crack position, $h / H$, and crack angle, $\beta$, on normalized mode II SIF for slant edge cracks with crack length, $a / W=0.3$
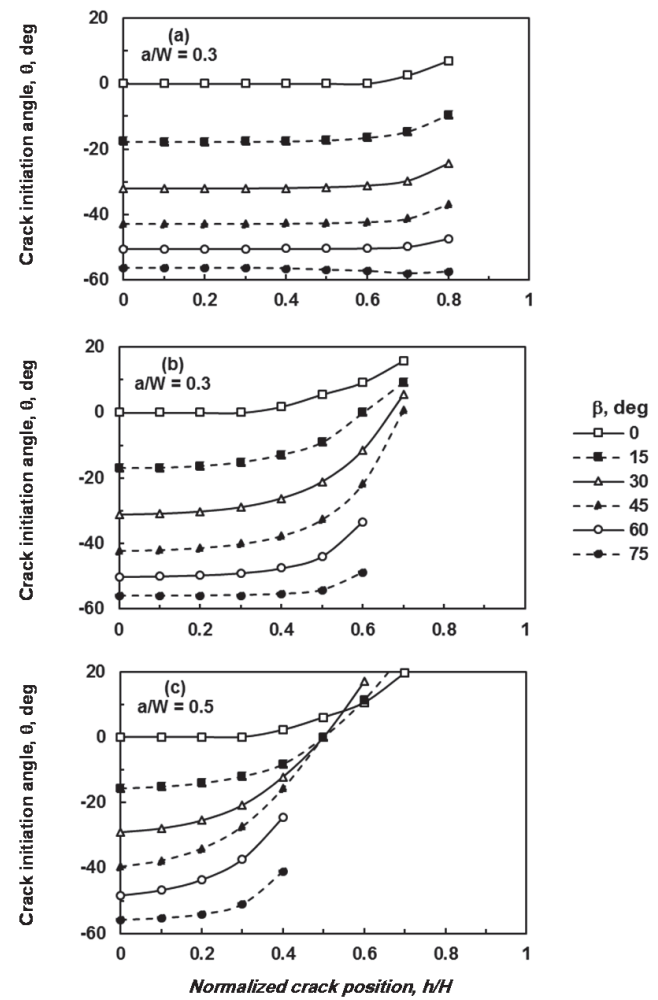

Fig. 8. Effect of crack position, $h / H$, and crack angle, $\beta$, on first crack initiation angle, $\theta$, at different crack lengths, $a / W$

As shown in Fig. 8(a), for the same crack angle and $a / W=0.1$, the crack initiation angle is nearly the same for crack positions near to the middle of the plate, when $h / H \leq 0.6$. However, as the crack gets closer to the top of the plate there is an increase of crack initiation angle. On the other hand, for longer cracks, i.e. $a / W=0.5$, the crack position, $h / H$, becomes more effective on crack initiation angle as shown in Fig. 8(c). It is noticed that as $h / H$ becomes close to 1 , the crack initiation approaches.

\section{Conclusions}

Mixed mode I/II SIFs were numerically computed for slant edge-cracked finite plate under remotely applied tensile stress. The effects of the crack length to plate width ratio, crack inclination angle, crack location to plate height ratio on crack initiation angles were evaluated. The results can support the following conclusions:

(1) In general, modes I and II SIF increase with increasing crack length. However, the rate of increase in mode I SIF decreases with increasing the main crack angle.

(2) For the same crack length, mode II SIF increases with increasing crack angle to reach a maximum value followed by a decrease in mode II SIF.

(3) Crack locations becomes more significant on mode I and II SIF as the crack length increases and location is near the top edge of the plate.

(4) The first crack initiation angle depends on crack length, crack location, and crack angle. 


\section{References}

ABAQUS Users, 2014, Version 6.14-1. Dassault Systémes Simulia Corp., Providence, RI.

Abd-Elhady, A. (2013). Mixed mode I/II stress intensity factors through the thickness of disc type specimens. Engineering Solid Mechanics, 1(4), 119-128.

Akbardoost, J., Ayatollahi, M. R., Aliha, M. R. M., Pavier, M. J., \& Smith, D. J. (2014). Size-dependent fracture behavior of Guiting limestone under mixed mode loading. International Journal of Rock Mechanics and Mining Sciences, 71, 369-380.

Akbardoost, J. (2014). Size and crack length effects on fracture toughness of polycrystalline graphite. Engineering Solid Mechanics, 2(3), 183-192.

Aliha, M. R. M., Ayatollahi, M. R., Smith, D. J., \& Pavier, M. J. (2010). Geometry and size effects on fracture trajectory in a limestone rock under mixed mode loading. Engineering Fracture Mechanics, 77(11), 2200-2212.

Aliha, M. R. M., \& Ayatollahi, M. R. (2009). Brittle fracture evaluation of a fine grain cement mortar in combined tensile-shear deformation. Fatigue \& Fracture of Engineering Materials \& Structures, 32(12), 987-994.

Aliha, M. R. M., Hosseinpour, G. R., \& Ayatollahi, M. R. (2013). Application of cracked triangular specimen subjected to three-point bending for investigating fracture behavior of rock materials. Rock Mechanics and Rock Engineering, 46(5), 1023-1034.

Aliha, M. R. M., \& Ayatollahi, M. R. (2012). Analysis of fracture initiation angle in some cracked ceramics using the generalized maximum tangential stress criterion. International Journal of Solids and Structures, 49(13), 1877-1883.

Aliha, M. R. M., \& Ayatollahi, M. R. (2013). Two-parameter fracture analysis of SCB rock specimen under mixed mode loading. Engineering Fracture Mechanics, 103, 115-123.

Aliha, M. R. M., Bahmani, A., \& Akhondi, S. (2015a). Numerical analysis of a new mixed mode I/III fracture test specimen. Engineering Fracture Mechanics, 134, 95-110.

Aliha, M. R. M., Bahmani, A., \& Akhondi, S. (2015b). Determination of mode III fracture toughness for different materials using a new designed test configuration. Materials \& Design, 86, 863-871.

Aliha, M. R. M., Bahmani, A., \& Akhondi, S. (2016a). Mixed mode fracture toughness testing of PMMA with different three-point bend type specimens. European Journal of Mechanics-A/Solids, $58,148-162$.

Aliha, M. R. M., Bahmani, A., \& Akhondi, S. (2016b). A novel test specimen for investigating the mixed mode I+ III fracture toughness of hot mix asphalt composites-Experimental and theoretical study. International Journal of Solids and Structures, 90, 167-177.

Arcan, M., Hashin, Z. A., \& Voloshin, A. (1978). A method to produce uniform plane-stress states with applications to fiber-reinforced materials. Experimental Mechanics, 18(4), 141-146.

Ayatollahi, M. R., \& Aliha, M. R. M. (2009). Analysis of a new specimen for mixed mode fracture tests on brittle materials. Engineering Fracture Mechanics, 76(11), 1563-1573.

Ayatollahi, M. R., \& Aliha, M. R. M. (2011). On the use of an anti-symmetric four-point bend specimen for mode II fracture experiments. Fatigue \& Fracture of Engineering Materials \& Structures, 34(11), 898-907.

Ayatollahi, M. R., Aliha, M. R. M., \& Saghafi, H. (2011). An improved semi-circular bend specimen for investigating mixed mode brittle fracture. Engineering Fracture Mechanics, 78(1), 110-123.

Ayhan, A. O. (2004). Mixed mode stress intensity factors for deflected and inclined surface cracks in finite-thickness plates. Engineering Fracture Mechanics, 71(7), 1059-1079.

Azlan, M. A., \& Ismail, A. E. (2014). Effect of mechanical mismatch on the stress intensity factors of inclined cracks under mode I tension loading. Applied Mechanics and Materials, International Integrated Engineering Summit, 129-133

Barsoum, R. S. (1976). On the use of isoparametric finite elements in linear fracture mechanics. International Journal for Numerical Methods in Engineering, 10(1), 25-37.

Barsoum, R. S. (1977). Triangular quarter-point elements as elastic and perfectly-plastic crack tip elements. International Journal for numerical Methods in engineering, 11(1), 85-98. 
Bhadauria, S. S., Pathak, K. K., \& Hora, M. S. (2010). Finite element modeling of crack initiation angle under mixed mode (I/II) fracture. Journal of Solid Mechanics, 2, 231-247.

Chang, K. J. (1981). On the maximum strain criterion - a new approach to the angled crack problem. Engineering Fracture Mechanics, 14(1), 107-124.

Ewing, P. D., Swedlow, J. L., \& Williams, J. G. (1976). Further results on the angled crack problem. International Journal of Fracture, 12(1), 85-93.

Erdogan, F., \& Sih, G. C. (1963). On the crack extension in plates under plane loading and transverse shear. Journal of Basic Engineering, 85(4), 519-525.

Fayed, A. S. (2008). Size Effect of Asymmetric Four Point Bend Specimen on Crack Propagation in Ceramics. ASJCE Fac. Eng. Ain Shams Univ., Cairo, 1(1), 227-237.

Hammouda, M. M. I., Fayed, A. S., \& Sallam, H. E. M. (2002). Mode II stress intensity factors for central slant cracks with frictional surfaces in uniaxially compressed plates. International Journal of Fatigue, 24(12), 1213-1222.

Hammouda, M. M. I., Pasha, R. A., \& Fayed, A. S. (2007). Modelling of cracking sites/development in axial dovetail joints of aero-engine compressor discs. International Journal of Fatigue, 29(1), 3048.

Hammouda, M. M. I., Fayed, A. S., \& Sallam, H. E. M. (2004). Stress intensity factors of a central slant crack with frictional surfaces in plates with biaxial loading. International Journal of Fracture, 129(2), 141-148.

Henshell, R. D., \& Shaw, K. G. (1975). Crack tip finite elements are unnecessary. International Journal for Numerical Methods in Engineering, 9(3), 495-507.

Hussain, M. A., Pu, S. L., \& Underwood, J. (1974, January). Strain energy release rate for a crack under combined mode I and mode II. In Fracture Analysis: Proceedings of the 1973 National Symposium on Fracture Mechanics, Part II. ASTM International.

Kanninen, M. F., \& Popelar, C. L. (1985). Advanced fracture mechanics. Newyork: Oxford University Press.

Khan, S. M., \& Khraisheh, M. K. (2000). Analysis of mixed mode crack initiation angles under various loading conditions. Engineering Fracture Mechanics, 67(5), 397-419.

Mirsayar, M. M., Aliha, M. R. M., \& Samaei, A. T. (2014). On fracture initiation angle near bi-material notches-Effects of first non-singular stress term. Engineering Fracture Mechanics, 119, 124-131.

Mirsayar, M., \& Samaei, A. (2014). Application of maximum tangential stress criterion in determination of fracture initiation angles of silicon/glass anodic bonds. Engineering Solid Mechanics, 2(3), 145-150.

Mirsayar, M. (2014). A new mixed mode fracture test specimen covering positive and negative values of T-stress. Engineering Solid Mechanics, 2(2), 67-72.

Mirlohi, S., \& Aliha, M.R.M. (2013). Crack growth path prediction for the angled cracked plate using higher order terms of Williams series expansion. Engineering Solid Mechanics, 1(3), 77-84.

Nuismer, R. J. (1975). An energy release rate criterion for mixed mode fracture. International Journal of Fracture, 11(2), 245-250.

Petit, C., Vergne, A., \& Zhang, X. (1996). A comparative numerical review of cracked materials. Engineering Fracture Mechanics, 54(3), 423-439.

Richard, H. A., \& Benitz, K. (1983). A loading device for the creation of mixed mode in fracture mechanics. international Journal of Fracture, 22(2), R55-R58.

Sih, G. C., \& Macdonald, B. (1974). Fracture mechanics applied to engineering problems-strain energy density fracture criterion. Engineering Fracture Mechanics, 6(2), 361-386.

Tada, H. I. R. O. S. H. I., Paris, P. C., \& Irwin, G. R. (2000). The analysis of cracks handbook. New York: ASME Press, 2, 1.

Theocaris, P. S., \& Papadopoulos, G. A. (1984). The influence of geometry of edge-cracked plates on $\mathrm{K}_{\mathrm{I}}$ and $\mathrm{K}_{\mathrm{II}}$ components of the stress intensity factor, studied by caustics. Journal of Physics D: Applied Physics, 17(12), 2339-2349. 
(C) 2017 by the authors; licensee Growing Science, Canada. This is an open access article distributed under the terms and conditions of the Creative Commons Attribution (CC-BY) license (http://creativecommons.org/licenses/by/4.0/). 